\title{
Alimentação como um direito humano: perspectivas éticas e bioéticas
}

\author{
Food as a human right: ethical and bioethical perspectives \\ La alimentación como derecho humano: perspectivas éticas y bioéticas
}

Elaine de Oliveira Zanini

ORCID: https://orcid.org/0000-0002-5098-7857

Universidade Estadual do Oeste do Paraná, Brasil

E-mail: elainezanini@gmail.com

Simone Cesario Soares

ORCID: https://orcid.org/0000-0002-4219-5729

Universidade Estadual do Oeste do Paraná, Brasil

E-mail: ccsimone@hotmail.com

Alvori Ahlert

ORCID: https://orcid.org/0000-0001-9984-6409 Universidade Estadual do Oeste do Paraná, Brasil

E-mail: alvoriahlert@yahoo.com.br

\begin{abstract}
Resumo
A busca pelo desenvolvimento perpassa a dignidade humana, naquilo que é essencial ao homem, à alimentação, sendo necessário pensar novas formas e processos produtivos que considerem a natureza como bem essencial. Pensar a sustentabilidade é pensar em uma sociedade mais equitativa e igualitária, garantindo modos de vida mais saudáveis e dignos. Destarte a pesquisa objetivou compreender as dimensões envolvidas no que é essencial aos seres humanos, o ato de comer, refletindo acerca dos meios de produzir e consumir considerando a economia de base capitalista. O trabalho foi desenvolvido através de metodologia bibliográfica, utilizando-se de artigos científicos, dados de institutos de pesquisas e organizações sociais, bem como leis e diretrizes acerca da temática, segurança alimentar. Como resultado, a pesquisa atestou que, apesar das legislações vigentes, tratados e acordos de dimensão nacional e internacional, o problema da fome permanece uma realidade bem presente, sendo necessárias ações efetivas da sociedade e do estado para tornarem a alimentação um direito humano inalienável.
\end{abstract}

Palavras-chave: Segurança alimentar; Dignidade humana; Ética; Bioética.

\begin{abstract}
The search for development goes through human dignity, in what is essential to man, food, being necessary to think of new forms and productive processes that consider nature as an essential good. Thinking about sustainability is thinking about a more equitable and egalitarian society, ensuring healthier and more dignified ways of life. Thus, the research aimed to understand the dimensions involved in what is essential to human beings, the act of eating, reflecting on the means of production and consumption considering the capitalist-based economy. The work was developed through bibliographic methodology, using scientific articles, data from research institutes and social organizations, as well as laws and guidelines on the theme, food security. As a result, the research confirmed that, despite the current legislation, treaties, and national and international agreements, the problem of hunger remains a very present reality, and effective actions are needed from society and the state to make food an inalienable human right.
\end{abstract}

Keywords: Food security; Human dignity; Ethics; Bioethics.

\begin{abstract}
Resumen
La búsqueda del desarrollo pasa por la dignidad humana, en lo que es esencial para el hombre, la alimentación, siendo necesario pensar en nuevas formas y procesos productivos que consideren la naturaleza como un bien esencial. Pensar en la sostenibilidad es pensar en una sociedad más equitativa e igualitaria, que garantice estilos de vida más saludables y dignos. Así, la investigación pretendía comprender las dimensiones implicadas en lo que es esencial para el ser humano, el acto de comer, reflexionando sobre los medios de producción y consumo considerando la economía de base capitalista. El trabajo se desarrolló a través de la metodología bibliográfica, utilizando artículos científicos, datos de institutos de investigación y organizaciones sociales, así como leyes y directrices sobre el tema, la seguridad alimentaria. La investigación demostró que, a pesar de la legislación, los tratados y los acuerdos nacionales e internacionales existentes, el problema del hambre sigue siendo un problema muy real, que requiere acciones eficaces por parte de la sociedad y el Estado para hacer de la alimentación un derecho humano inalienable.
\end{abstract}

Palabras clave: Seguridad alimentaria; Dignidad humana; Ética; Bioética. 


\section{Introdução}

Com a globalização, vários problemas como crise mundial, poluição, concentração de renda, desemprego, escassez de água e recursos naturais, entre outros são agravados. No entanto, esses problemas estão sendo potencializados em virtude da pandemia COVID-19, suscitando a urgência na elaboração de estratégias conjuntas entre os países para assegurarem aos cidadãos seus direitos básicos. Dentre eles, o direito ao acesso regular a alimentos de qualidade, o qual é deve ser garantido para todos os cidadãos brasileiros por meio da legislação brasileira (Brasil, 2020).

A FAO (2018) relata que países como Brasil, Cuba e o Uruguai são líderes na luta contra a fome, com percentual maior que a média dos países da América Latina e Caribe, que é de 6,1\%, outro dado relevante neste contexto é que a população desses países se alimentam de produtos pouco nutritivos e os consomem em pouca quantidade, no entanto, alguns países da América Latina, dentre eles o Brasil, produzem frutas e legumes em percentuais maiores aos requisitos mínimos, $39 \%$ no caso do nosso País (FAO, 2018). Tais dados evidenciam que o problema não está na quantidade de alimentos produzidos, mas sim no acesso a eles.

Um fator determinante para o acesso ao alimento é o financeiro, que sofre as consequências da pandemia COVID-19, com o índice de desemprego finalizando o trimestre do mês de julho de 2020 em 13,8\%, a maior taxa desde o ano de 2012 (IBGE, 2020a), configurando um cenário que acarreta impacto diretamente as ações nos âmbitos de acesso aos alimentos e da segurança alimentar e nutricional, limitando o poder de consumo e, consequentemente, o acesso à alimentação, agravando a situação das pessoas vítimas da insegurança alimentar e nutricional, as quais não tem condições financeiras para atender às suas necessidades diárias básicas (FAO, 2017, 2018; FAO, CEPAL, 2020).

Diante disso, o presente estudo objetiva evidenciar as legislações vigentes, bem como tratados e acordos de dimensões nacional e internacional relacionados com o problema da fome presente, que se amplia com a pandemia em curso, agravando esta realidade em grandes parcelas da sociedade mundial. Questionamos sobre os desafios dos Estados nacionais e dos organismos internacionais de cooperação e solidariedade para considerar a alimentação como um direito inalienável e atuar na promoção da saúde humana e na segurança alimentar e nutricional, fomentando a produção sustentável de alimentos saudáveis e seguros. O objetivo principal dessa investigação é compreender as dimensões envolvidas na relação entre alimentação, acesso ao alimento, segurança alimentar e nutricional no contexto ético e bioético.

\section{Metodologia}

Em relação à metodologia aplicada neste estudo, esta pesquisa caracteriza-se como bibliográfica, com caráter exploratório e qualitativo. Para a coleta dos dados, foram realizadas pesquisas em plataformas como: Scielo, FAO (Organização das Nações Unidas para a Alimentação e a Agricultura), Nações Unidas, CEPAL (Comissão Econômica para a América Latina e o Caribe) e PLANSAN (Plano Nacional de Segurança Alimentar e Nutricional), tais pesquisas possibilitaram uma maior compreensão da relação do direito ao acesso ao alimento e a segurança alimentar e nutricional no contexto ético e bioético.

Este estudo é definido como uma revisão bibliográfica, com caráter exploratório e qualitativo, o qual visou discutir e apresentar a segurança alimentar e nutricional numa perspectiva ética, pautado na coleta de dados de pesquisas já realizadas anteriormente é considerado para Gil (2010), uma revisão bibliográfica. Para este artigo várias plataformas conceituadas sobre os temas discutidos foram consultadas, são elas: Scielo, FAO (Organização das Nações Unidas para a Alimentação e a Agricultura), Nações Unidas, CEPAL (Comissão Econômica para a América Latina e o Caribe) e PLANSAN (Plano Nacional de Segurança Alimentar e Nutricional). 
Para as buscas nas plataformas citadas foram utilizadas as palavras-chaves: desenvolvimento sustentável, ética, pandemia, segurança alimentar e nutricional no período de setembro a novembro de 2020, possibilitando uma maior compreensão da relação do alimento, acesso a ele e a segurança alimentar e nutricional no contexto ético.

Este artigo está subdivido em quatro seções, na primeira seção apresenta-se a introdução com a contextualização do tema, no referencial teórico encontra-se a discussão sobre o direito humano ao acesso ao alimento e a sua relação com a segurança alimentar e nutricional e a ética e bioética. Por fim, os procedimentos metodológicos são apresentados, as conclusões finais e as referências bibliográficas utilizadas na pesquisa.

\section{Resultados e Discussão}

\subsection{Comer: um direito humano universal}

As preocupações em relação à segurança alimentar e nutricional já vem sido discutidas por órgãos como a Organização das Nações Unidas para a Alimentação e a Agricultura (FAO) há alguns anos, com objetivo de elaborar ações que assegurem alimento com teor nutricional equilibrado para em média 10 bilhões de pessoas no ano de 2050 e principalmente, para que esse alimento seja acessível a todos, considerando que, em âmbito mundial, a produção de alimentos é suficiente para alimentar toda a população atual (FAO, 2017a).

Um dos fatores que comprometem vencer esses desafios é a desigualdade, “(...) a riqueza se tornou extremamente concentrada, de forma acentuada na faixa do $0,1 \%$ da população mais abastada) gerando uma concentração de poder político" (Chomsky, 2017, p. 101), como consequências drásticas podemos ter mudanças do humano e do meio ambiente. Em relação ao Brasil, de acordo com dados do IBGE de 2020, no ano de 2019, $1 \%$ da população brasileira ganhava 33,7 vezes mais (média de $\mathrm{R} \$ 28.659,00$ ) do que $50 \%$ da população com renda de $\mathrm{R} \$ 850,00$, expondo a profunda desigualdade entre ricos e pobres no nosso País (IBGE, 2020), esse fato está relacionado com a segurança alimentar e nutricional.

O tema segurança alimentar teve a devida atenção no Brasil, somente a partir do encontro da Cúpula Mundial de Alimentação em 1997, momento em que o País elaborou estratégias com a finalidade de atender a política de segurança alimentar e nutricional (Almeida, 2007). Neste contexto, implementa-se o Sistema Nacional de Segurança Alimentar e Nutricional (SISAN) (PLANSAN, 2011) e a Câmara Interministerial de Segurança Alimentar e Nutricional (CAISAN) e no ano de 2010 é aprovado, por meio do Decreto 7.272, a Política Nacional de Segurança Alimentar e Nutricional (PNSA). Um ano depois, em 2011, foi aprovado I Plano Nacional de Segurança Alimentar e Nutricional (PLANSAN) (PLANSAN, 2017), o qual foi reformulado e apresentado em 2018 como o II Plano Nacional de Segurança Alimentar e Nutricional (PLANSAN), fomentando a sustentabilidade na produção de alimentos e a transição agroecológica, o fortalecimento da agricultura familiar e a segurança alimentar e nutricional (PLANSAN, 2018).

Tais definições também estão associadas à Lei Orgânica de Segurança Alimentar e Nutricional (LOSAN), $n^{\circ} 11.346$ do ano de 2006, criada para promover a produção usando técnicas sustentáveis e a comercialização de produtos saudáveis e seguros. Além dessas ações o País tinha atrelado ao SISAN, o Conselho Nacional de Segurança Alimentar e Nutricional (CONSEA), o qual foi extinto por meio da Medida Provisória nº 870 e Lei n 13.844, autorizada pelo presidente Jair Bolsonaro no ano de 2019 (BRASIL, 2020a). Essa decisão debilita as ações em relação à segurança alimentar e nutricional, uma vez que o conselho atendia as decisões provenientes das Conferências Nacionais de Segurança Alimentar e Nutricional (CNSAN), elaborava, controlava e monitorava as políticas públicas com esse viés e ainda era responsável por apresentar ao CAISAN as sugestões e priorizá-las no PLANSAN (CONSEA, 2017). 
Questões relacionadas ao acesso aos alimentos e à insegurança alimentar e nutricional poderão ser agravadas com os efeitos da pandemia. Esta última tem tido aumentos significativos na América do Sul, impactando diretamente os índices na América Latina e Caribe com um crescimento de 22,9\% em 2014 para 31,7\% em 2019 (SOFI, 2020).

O direito humano à alimentação adequada está no artigo 25 da Declaração Universal dos Direitos Humanos de 1948. Esta definição faz parte de outros dispositivos do Direito Internacional, como o artigo 11 do Pacto de Direitos Econômicos, Sociais e Culturais e o Comentário Geral no 12 da ONU.

A alimentação adequada foi estabelecida pela Constituição Brasileira de 1988 (Brasil, 2020), ou seja, um compromisso ético com a população, principalmente a mais vulnerável. Dentre os fundamentos da Constituição estão: “a dignidade da pessoa humana, erradicar a pobreza e a marginalização e reduzir as desigualdades sociais e regionais" (Brasil, 2020).

Assim se faz necessário compreender quais são os aspectos referente à alimentação adequada, introduzida pela Lei $\mathrm{n}^{\circ}$ 11.346/2006, através da implantação do Sistema Nacional de Segurança Alimentar e Nutricional (SISAN), e que perpassa vários segmentos, sejam eles sociais, econômicos, de caráter, político, ético e mesmo jurídico (Rosendo et al., 2019).

O direito à alimentação adequada é um direito humano inerente a todas as pessoas de ter acesso regular, permanente $\mathrm{e}$ irrestrito, quer diretamente ou por meio de aquisições financeiras, a alimentos seguros e saudáveis, em quantidade e qualidade adequadas e suficientes, correspondentes às tradições culturais do seu povo e que garanta uma vida livre do medo, digna e plena nas dimensões física e mental, individual e coletiva (Brasil, 2010, p. 15).

Neste sentido, em relação ao cenário nacional, no ano de 2003, o país apresentou uma melhora nos índices de insegurança alimentar e nutricional e nos índices de pobreza e extrema pobreza, principalmente com a implantação do Programa Fome Zero do Governo Federal e outras políticas públicas, visando combater à fome e à pobreza (PLANSAN, 2011).

Outros programas foram implantados a fim de estimular o consumo de produtos orgânicos e fortalecer a agricultura familiar, por meio das compras governamentais o Governo Federal aprovou o Programa de Aquisição de Alimentos (PAA) e o Programa Nacional de Alimentação Escolar (PNAE), ambos para a compra de alimentos produzidos pela agricultura familiar. Em 2009 foi aprovada a Lei da Alimentação Escolar n 11.947 que estabelece que as escolas comprem no mínimo 30\% de alimentos orgânicos para oferecer aos estudantes uma alimentação saudável e com qualidade nutricional adequada, garantindo a segurança alimentar e nutricional (Santos et al., 2017). Dentre as diretrizes, no Art. 2 da Lei fica explícito o compromisso ético com os estudantes:

O direito à alimentação escolar, visando a garantir segurança alimentar e nutricional dos alunos, com acesso de forma igualitária, respeitando as diferenças biológicas entre idades e condições de saúde dos alunos que necessitem de atenção específica e aqueles que se encontram em vulnerabilidade social (Brasil, 2020d).

Especificamente no ano de 2017, o Brasil estabeleceu diretrizes no Plano de Segurança Alimentar e Nutricional de 2017 para fortalecer a agricultura familiar e promover a segurança alimentar e nutricional, com o intuito de reduzir os gastos com a saúde pública, a qual cresceu 42\% em dez anos (R\$ 78,5 bilhões - R \$ 111,8 bilhões) (Brasil, 2017) e também planejava atenuar a incidência dos casos de obesidade - o percentual de pessoas obesas com mais de 18 anos cresceu 15,5\%, entre 1980 e 2016 (FAO, 2018) - avivando uma alimentação saudável, com o consumo de frutas de hortaliças em adultos, a meta era de aumentar em 6,5\% o percentual desse consumo, qual até então era de 36,5\% (PLANSAN, 2017).

Ainda de acordo com o PLANSAN, o Governo Federal também visava reduzir o consumo de refrigerantes e suco artificial em torno de $6,8 \%$ o percentual de $20,8 \%$, e por fim, fomentar a união mundial na elaboração de políticas com o 
propósito de promover o desenvolvimento rural sustentável, a inovação, a comercialização e o abastecimento (PLANSAN, 2017).

Mesmo com os esforços do Governo Federal, existia uma grande parte da população em situação de insegurança alimentar (CONSEA, 2009) e atualmente estamos no ranking de aumento da fome pela quinta vez consecutiva, segundo dados da pesquisa que expõe o Estado da Segurança Alimentar e Nutricional no Mundo em 2020 (SOFI, 2020). Com os efeitos da pandemia, estima-se que esses índices piorem, há previsão de que neste ano de 2020 em torno 28,7 milhões de pessoas vivam em situação de pobreza (FAO; CEPAL, 2020) e que até 2030, a fome cresça para 9,5\%, contemplando em torno de 67 milhões de pessoas (SOFI, 2020).

Dados do ano de 2018 já evidenciavam que os países que lideravam a luta contra a fome na América Latina e Caribe eram o Brasil, Cuba e o Uruguai, a população desses países consumiam pouca quantidade de alimentos, além disso, o teor nutritivo era insuficiente, tais dados fizeram com que o percentual da fome fosse maior que a média da região, que é de 6,1\%. Em contrapartida, um fator importante ressaltado pela mesma pesquisa é que países da América Latina como o Brasil, Chile, Equador, Argentina, México, Guatemala não enfrentam problemas em relação a produção e oferta de alimentos, como frutas e legumes e ainda, no Brasil, Honduras e Argentina, México, a produção desse tipo de alimento era até maior aos requisitos minimos, respectivamente, em 39\%, mais de 60\% e 50\% (FAO, 2018).

Como pode ser observado o problema está no acesso ao alimento e não na capacidade de produção. Neste sentido, segundo os dados da pesquisa realizada na América Latina e Caribe pelo CEPAL (2020), por conta da perda de renda de 5\% da população economicamente ativa o aumento da pobreza será em torno de 3,5 pontos percentuais. Os dados do IBGE relatam a situação do índice em relação ao desemprego no trimestre encerrado em julho deste ano de 2020, o índice é de 13,8\% e é considerada a maior taxa desde o ano de 2012 (IBGE, 2020a).

Ainda para o ano de 2020, estimou-se um crescimento econômico negativo que, para a FAO (2017, 2018), impacta diretamente nas medidas relacionadas aos problemas da segurança alimentar e nutricional e diminuem o poder de consumo, limitando ainda mais o acesso à alimentação e a saúde, não esquecendo das pessoas vulneráveis que vivem em insegurança alimentar e nutricional, uma vez que não possuem dinheiro para atender às suas necessidades mais básicas (FAO, 2018; FAO, CEPAL, 2020).

O custo da alimentação saudável e nutritiva é um fator que limita e até impede uma alimentação adequada. As pesquisas realizadas pela FAO em 2017 e 2018 e pela SOFI em 2020, evidenciam essa questão, na qual comprovam que aalimentos do tipo fast food, processados, pouco nutritivos custam menos, uma vez que, o custo por caloria de alimentos como frutas e vegetais é maior do que o custo do açúcar (FAO, 2017, 2018; SOFI, 2020).

Ainda, outra pesquisa realizada pela Associação de Promoção dos Orgânicos (ORGANIS) apresenta um dado importante do Brasil, as pessoas que possuem menor poder aquisitivo e menor nível de escolaridade consomem menos alimentos orgânicos, ou seja, alimentos saudáveis e seguros, ricos em nutrientes, esse índice é de $9 \%$ para população com baixo recurso financeiro e $8 \%$ para população com ensino fundamental incompleto, um comparativo pode ser feito com a média de consumo desses alimentos no País que é de 15\% (MAPA, 2019).

Quando se trata dos países da América Latina e o Caribe, dentre todas as regiões do mundo, a compra de alimentos com capacidade energética mínima diária de uma pessoa (US\$1,06) tem um custo maior que a média mundial que é de $34 \%$ (SOFI, 2020). Segundo a FAO (2017), uma alimentação inadequada, com muitos alimentos processados, produzidos com grande quantidade de açúcar, gordura e sal, promovem a incidência de várias doenças, dentre elas, as doenças crônicas como hipertensão, diabetes e câncer, aonde 70\% das pessoas morrem em decorrência destes problemas de saúde no Brasil e também aumentam o risco de sobrepeso e a obesidade (FAO, 2017). 
Até o ano de 2030, acredita-se que $70 \%$ da população sofram com sobrepeso e $30 \%$ com obesidade nesta região, atualmente a média mundial de sobrepeso é de 5,6\% e em torno de 7,5\% das crianças menores de 5 anos estão acima do peso na América Latina e Caribe (SOFI, 2020), no Brasil, o índice da população obesa com mais de 18 anos aumentou 15,5\% em trinta e seis anos (1980-2016) (FAO, 2018).

Estratégias a fim de amenizar os problemas de sobrepeso e obesidade por exemplo, estão sendo implantadas pelos países da América Latina e do Caribe, uma delas se refere a apresentação das informações nutricionais no rótulo frontal das embalagens dos alimentos, a regulação da publicidade em relação aos alimentos e a restrição da venda de alguns produtos ricos em açúcar, gordura, sódio e calorias principalmente nas escolas (FAO, 2018).

Além dessas preocupações mencionadas anteriormente, precisamos de ações para enfrentarmos as consequências da pandemia, a qual está desnudando e agravando todos os problemas já existentes. Assim, todos países precisam se unir para elaborem ações para amenizerem os efeitos negativos da pandemia COVID-19, lhe proporcionando uma vida digna prevista na legislação brasileira.

Neste sentido, os presidentes dos países do Mercado Comum do Sul (MERCOSUL), dentre eles o Brasil, "reiteraram o seu compromisso com a plena validade da democracia, as garantias fundamentais e do Estado de Direito, bem como a proteção e promoção dos direitos humanos das pessoas" (MERCOSUL, 2020a). Eles se reuniram e elaboraram algumas ações, as quais podem ser observadas no Quadro 1 abaixo, para solucionarem os problemas pós pandemia, dentre elas destaca-se:

Quadro 1: Algumas recomendações de políticas para solucionar os problemas pós-pandemia.

1. É necessário um estímulo fiscal de quantidade suficiente para apoiar os serviços de saúde e proteger a renda e o emprego e garantir o suprimento bens essenciais ininterruptos, em particular produtos farmacêuticos, equipamentos médico, comida e energia. Os gastos com saúde neste momento são uma prioridade, especialmente nos países sistemas de saúde fracos e fragmentados.

2. É necessário reforçar os sistemas de proteção social para apoiar as populações vulneráveis. Programas não contributivos, como transferências diretas, devem ser ampliados dinheiro para os benefícios mais vulneráveis, desemprego, subemprego e trabalho por conta própria, crédito sem juros a empresas para pagamento de salários e deferimentos de pagamento de empréstimos. Apoio imediato deve ser fornecido a HSH, trabalhadores de baixa renda e setor informal. Medidas como a não cobrança das contas de água devem ser consideradas, eletricidade e Internet para pessoas de baixa renda pelo período da pandemia.

3. Levantar sanções aos países sujeitos a elas permitindo seu acesso a alimentos, suprimentos médicos, testes de COVID-19 e assistência médica, é um tempo de solidariedade, não de exclusão.

Fonte: CEPAL (2020, p. 13-14)

Além disso, os países fizeram um comunicado em conjunto, na área da saúde, tal comunicado afirma que os países do MERCOSUL compartilharam informações sobre a situação epidemiológica e medidas sanitárias desde o início do COVID-19 na região na tentativa de amenizar o impacto para a população e se comprometerem em elaborar ações regionais para vigilância e assistência médica e realizarem reuniões de coordenação periódicas setoriais para a vigilância e monitoramento do COVID-19 (MERCOSUL, 2020).

Ainda de acordo com o comunicado, os países também acordaram "a transferência de tecnologias e a conclusão de acordos que permitam a disponibilidade de vacinas, tratamentos e novas tecnologias desenvolvidas em resposta ao COVID-19, as medidas harmonizadas de vigilância epidemiológica e controle da saúde nas fronteiras e promover o acesso a medicamentos" (MERCOSUL, 2020). As discussões a respeito do meio ambiente ressaltam a importância de focar no desenvolvimento sustentável, elaborando políticas públicas para a preservação da natureza, pensando nas pessoas no contexto da economia e meio ambiente saudáveis.

Já em relação à cidadania, os países do MERCOSUL reiteraram os princípios base do Tratado de Assunção e promoção da união dos seus cidadãos, visando o bem-estar da população. Além disso, reasseguraram que irão unir esforços 
para prevenir e combater o COVID-19, atender outras demandas de saúde e para o renascimento econômico da região (MERCOSUL, 2020).

Para a CEPAL, a pandemia possibilita novos rumos à geopolítica da globalização e as medidas tomadas podem dar origem a um modelo de desenvolvimento mais sustentável e mais inclusivo (CEPAL, 2020).

De modo geral, o apoio à segurança alimentar nutricional e um desenvolvimento sustentável, condiz com a procura e necessidade de uma alimentação segura e saudável e auxilia na diminuição dos índices de insegurança alimentar e nutricional e ainda fortalece e incentiva a diversificação da agricultura familiar, principalmente na produção de produtos orgânicos, estimulando o consumo de alimentos saudáveis e seguros.

Neste cenário, é notório o aumento da busca por alimentos saudáveis e sem contaminantes por parte dos consumidores, fator que tem relação direta com o crescimento do consumo de produtos orgânicos, não somente no Brasil, mas no mundo todo (Brasil Ecológico, 2019). Uma prova disso são os números, em 2017, esse mercado movimentou cerca de US\$ 97 bilhões, beneficiando em média 3 milhões de produtores orgânicos numa área de 70 milhões de hectares, esses são os dados da Federação Internacional de Movimentos da Agricultura Orgânica (IFOAM).

No âmbito nacional, de acordo com a ORGANIS, o Brasil lidera este mercado na América Latina, em 2018, faturamos $20 \%$ a mais do que no ano de 2017, isso representa cerca R\$ 4 bilhões (MAPA, 2019) ainda houve um aumento da quantidade de produtores rurais cadastrados como produtores de alimentos, o Ministério da Agricultura relata que esse número cresceu três vezes em menos de dez anos (2010-2018), ocasionando um crescimento de 300\% em termos e unidade de produção, 22 mil unidades foram regularizadas somente no ano de 2019 (Brasil Ecológico, 2019).

Como forma de padronizar a produção deste tipo de alimentos, o Brasil elaborou e aprovou em dezembro de 2003, a Lei da Produção de Orgânicos $\mathrm{N}^{\circ} 10831$, a qual estabelece os requisitos para uma produção com sustentabilidade, visando o cuidado e respeito com o meio ambiente e a promoção da saúde humana, ofertando alimentos seguros, saudáveis e nutritivos de acordo com a procura cada vez maior dos consumidores por produtos com essas características (BRASIL, 2020b). O Art. $1^{\circ}$ da Lei estabelece que os produtores familiares “(...) adotem técnicas específicas, mediante a otimização do uso dos recursos naturais e socioeconômicos disponíveis e o respeito à integridade cultural das comunidades rurais, tendo por objetivo a sustentabilidade econômica e ecológica, a maximização dos benefícios sociais (...)” (Brasil, 2020b).

Questões como a sustentabilidade na produção de alimentos vem sendo cada vez mais discutida mundialmente (Sá et al., 2014). Para Altieri (2012), as propriedades agrícolas que produzem os alimentos fazendo maior uso de recursos locais, utilizam biomassa e nutrientes para recompor o solo, fazem uso efetivo dos processos ecológicos naturais e diversificam a produção de alimentos fomentam a segurança alimentar e a preservação do meio ambiente, uma vez que a produção de alimentos saudáveis e sustentáveis precisa estar ligados a preservação da biodiversidade (Martinelli, 2019).

A adoção de conceitos de sustentabilidade e desenvolvimento sustentável desde o início da produção até a comercialização é importante, pois os consumidores têm acesso a muita informação e estão cada vez mais exigentes (Sá et al., 2014. p. 02).

Diante do que foi exposto, é nítido que para a construção de um mundo pautado no desenvolvimento mais sustentável e na busca pela segurança alimentar nutricional precisa-se de um esforço coletivo entre os países e entre população e governos. Neste sentido, estratégias como a elaboração de políticas públicas e programas com esses vieses contribuem para assegurar o direito constitucional de acesso a uma alimentação segura, saudável e em quantidades suficientes para uma dieta equilibrada, consequentemente, diminui os gastos públicos com saúde, incentiva o consumo consciente e a produção de alimentos orgânicos pela agricultura familiar, fortalece este setor e preserva o meio ambiente. 


\subsection{Comer como um Princípio Ético e Bioético}

A ética nos obriga a olhar a questão do direito humano no acesso à segurança alimentar para além dos direitos civis e políticos historicamente priorizados no ocidente. Para Ahlert (2007), isso significa olhar para os Direitos Humanos na perspectiva do progresso emancipador, que valoriza os direitos civis e políticos, mas dá prioridade aos direitos econômicos e sociais. Segurança alimentar envolve o acesso a alimentos e à qualidade desses alimentos oriundos de um meio ambiente saudável. Por isso, a ética reclama a prioridade para os direitos econômicos e sociais, com mais intransigência ainda neste período de pandemia consorciado com uma forte atuação de políticas neoliberais concentradoras de renda e riqueza.

Los derechos económicos y sociales son los derechos relativos al trabajo, a una remuneración justa, a una jornada de trabajo no superior a las ocho horas, al descanso semanal, a vacaciones remuneradas, a igualdad de remuneración para trabajos iguales, a la libertad sindical, a la huelga, a seguridad social, a educación, a vivienda. Este conjunto de derechos se desarrollaron a partir de la Revolución Rusa, de la Constitución Mexicana de 1917 y de la Constitución del Weimar. Los derechos de cuarta generación son aquellos derivadas de la Declaración Universal de los Derecho del Hombre, de 1948. Esos derechos incluyen el derecho al medio ambiente sano, la paz y la autodeterminación de los pueblos (Ahlert, 2007, p. 7).

Com os desdobramentos da ética em bioética, a bioética passou a intensificar os temas relativos à vida dos seres humanos em seu cotidiano social. Conforme Westphal, “A bioética trata de questões ligadas a saúde pública, controle de natalidade, experimentação com animais, problemas ambientais, fome, justiça, e equidade sociais, bem como de humanização das ciências (...)” (Westphal, 2006, p. 97).

Desta forma, compreender a necessidade de sobrevivência do humano, precisamos conhecer um primeiro aspecto da moralidade, ou seja, a dignidade da pessoas humana. Neste sentido pode-se compreender que a dignidade da pessoa humana, é condição fundamental para a construção de uma sociedade mais justa e igualitária. Neste sentido Kant traz o conceito de imperativo categórico na medida em que considera que o valor do humano, não pode ser mensurado, tem valor em si mesmo. Assim coloca kant: "age de tal modo que consideres a humanidade, tanto em tua pessoa como na pessoa de todos os outros, sempre como fim e nunca como simples meio" (Kant, 2007, p. 69). Assim o imperativo sendo ele tanto no plano individual, quanto em sua relação com o outro não pode ser visto como simples meio.

Nesse sentido, a ideia fundamental desse imperativo é que por dever devemos respeitar o nosso próprio ser (pessoa) e também a pessoa de outrem como fim em si mesmo. Em outra passagem Kant afirma que: "no reino dos fins tudo tem um preço ou uma dignidade. Quando uma coisa tem preço, pode-se pôr em vez dela qualquer outra como equivalente, mas quando uma coisa está acima de todo preço, e portanto não permite equivalente, então ela tem dignidade” (Kant, 2007, p. 77).

Isso significaria que a relação com o outro possui valor em si mesmo, ou seja, se trata de um valor absoluto. Desta forma a relação do eu com o outro tem fim em si mesmo e não ocorre como meio pelo sujeito ético, inferindo desta forma a dignidade da pessoa humana como um todo, e não como um objeto ou coisa (Pereira, 2016). Assim podemos afirmar que o homem tem valor em si mesmo.

O ser humano compreendido na sua totalidade, confirmado nas palavras de Garcia: "a dignidade da pessoa humana corresponde à compreensão do ser humano na sua integridade física e psíquica, como autodeterminação consciente, garantida moral e juridicamente" (Garcia, 2004, p. 211).

Corroborando com o conceito de dignidade humana Sarlet afirma:

A qualidade intrínseca e distintiva reconhecida em cada ser humano que o faz merecedor do mesmo respeito e consideração por parte do Estado e da comunidade, implicando, neste sentido, um complexo de direitos e deveres fundamentais que assegurem a pessoa tanto contra todo e qualquer ato de cunho degradante e desumano, como venham a lhe garantir as condições existenciais mínimas para uma vida saudável, além de propiciar e promover sua 
participação ativa e co-responsável nos destinos da própria existência e da vida em comunhão com os demais seres humanos (Sarlet, 2007, p. 62).

O Brasil tem vivido momentos, onde fica claro cenário de insegurança alimentar, na medida em que se produz muito, no entanto a maior parte desta produção se destina a exportação, no qual outros países pagam mais, forçando um aumento interno de preço. Produtos considerados essenciais à cesta básica do brasileiro, que conforme dados apresentados pelo Departamento Intersindical de Estatística e Estudos Econômicos (DIEESE), registrou um aumento da cesta básica em 17 em capitais brasileiras, no mês de agosto de 2020, (DIEESE, 2020). E a consequência é um cenário de insegurança alimentar, que revela, o aumento das taxas de pobreza, e por consequência da fome. Hoffmann afirma que "o problema da fome no Brasil não se deve a pouca disponibilidade global de alimentos, mas sim à pobreza de grande parte da população" (Hoffmann, 1994, p. 08).

O modelo capitalista vigente, que segundo Burity (2010) causa ainda: "transformar, consumir, importar e exportar alimentos sem reproduzir modelos que gerem injustiça social, de forma sustentável, conservando e resgatando a diversidade produtiva e cultural de um povo" (Burity et al., 2010).

Neste sentido Pereira (2016), vem afirma que para que possamos saciar a necessidade de comer, temos que ter condições econômicas para tal, por meios próprios ou pela ação do Estado. Configurando o conceito de alimento apenas como mercadoria, cujo contexto econômico predatório privilegia os economicamente abastados. Desta forma, fica evidente que o alimento, é tratado como mercadoria sob os moldes de um capitalismo predatório. E não se garantindo a dignidade humana, ou seja, as condições mínimas para que se tenha uma vida digna, sem dor e sofrimento resultante de fome e doenças a ela associadas.

A questão alimentar representa uma gama de ações, e medidas em que possui implicações éticas, ou seja, pensada pelos meios de produção que frequentemente se valem da exploração humana, refletindo a quem destina-se os lucros desta produção. Compreender a dimensão alimentar significa considerar, a exploração do trabalho humano, do sofrimento animal, bem como a dimensão ambiental, uma vez que está em voga a uma economia de base capitalista, no qual se busca a grande produtividade a qualquer custo seja utilizando-se de agrotóxicos, sementes modificados geneticamente, seja pela extração de bens naturais de forma indiscriminada. Conforme cita Westphal: "O modelo econômico, aliado à falta de consciência de cada um de nós, está preparando uma realidade de calamidades" (Westphal, 2006, p. 92).

O desenvolvimento a partir de uma perspectiva econômica considera quase que exclusivamente as relações de mercado e suas variáveis. Sen (2011) aponta pra um descaso com relação à ética, bem como dos temais sociais e por consequência fortalecendo a desigualdade. Se fazendo necessário a não idealização de modelos, como cita Sen: “(...) o objetivo é esclarecer como podemos proceder para enfrentar as questões sobre a melhoria da justiça e a remoção da injustiça, em vez de oferecer soluções para questões sobre a natureza da justiça perfeita" (Sen, 2011, p. 11).

Já o imperativo bioético de Fritz Jahr se dá forma flexível, onde considera a necessidade de buscar um equilíbrio entre os valores e objetivos de vida dos seres vivos em sua luta pela sobrevivência em suas necessidades por alimento, por espaço e desenvolvimento, onde aponta para um sentimento ético, de empatia, compaixão e obrigações morais e sociais e os humanos devem uns para com os outros (Pessini, 2003).

\subsection{Bioética e a Alimentação Saudável}

Ao tratar da segurança alimentar não podemos deixar de considerar nosso contexto atual, onde no Brasil existem centenas de agrotóxicos liberados. O Brasil é um dos grandes produtores de insumos agrícolas do mundo. Conforme levantamento da safra de grãos 2019/2020, divulgado pela Companhia Nacional de Abastecimento (CONAB), indica que a 
produção brasileira está estimada em 245,8 milhões de toneladas, um aumento de 1,6\%, ou seja, 3,9 milhões de toneladas a mais em relação à safra 2018/2019 (CONAB, 2020).

No entanto o Brasil é um dos países do mundo onde mais se permite o uso de agrotóxicos. Esse fato foi mais intensificado na década de 1960, com o uso de adubos químicos e venenos. No ano de 2019, o Brasil já tinha autorizado cerca de 474 agrotóxicos. Com a implantação das sementes transgênicas foi cada vez mais justificado o uso de adubos químicos, bem como de agrotóxicos (Soares et. al., 2020).

Segundo dados da Agência Nacional de Vigilância Sanitária (ANVISA) e do Observatório da Indústria dos Agrotóxicos da Universidade Federal do Paraná (UFPR), divulgados durante o II Seminário sobre Mercado de Agrotóxicos e Regulação, realizado em Brasília, Distrito Federal, em abril de 2012, enquanto, nos últimos dez anos, o mercado mundial de agrotóxicos cresceu 93\%, o mercado brasileiro cresceu 190\% (Cassal et al., 2014, p. 02).

A aplicação de agrotóxicos de forma excessiva e descontrolada em lavouras o e tem sido considerado um importante agente de contaminação do solo e da água. Há um crescente aumento do grau de toxicidade, bem como de seus teores encontrados em diversos compartimentos ambientais, o consumo dessas águas ou suas reutilizações na agricultura e que podem resultar em riscos à saúde pública (Silvério et al., 2012).

Criando um contexto de produção alimentícia de insegurança, pois não basta ter acesso ao alimento, conforme estudos de Stoppelli (2005) os agrotóxicos estão presentes no alimento do brasileiro, em altos graus e com grande poder para afetar a saúde tanto da natureza quanto dos humanos.

A acumulação de agrotóxicos ao longo da cadeia alimentar, a exemplo dos inseticidas organoclorados, leva a um fenômeno ecológico chamado de bioma significação, que é o aumento das concentrações de uma determinada substância de acordo com o aumento do nível trófico (Stoppelli, 2005, p. 92).

A presença dos agrotóxicos nos alimentos, tendo sido evidenciado por pesquisas cientificas, nas quais conformam o nocividade causa por eles nos humanos. Um destes estudos epidemiológicos mostrou que a exposição ao DDT, um aumento das taxas de câncer de mama, alterações hormonais, aborto espontâneo, diminuição do peso dos bebês ao nascer e outras anomalias (Stoppelli, et al., 2005).

Deve-se reconhecer que a natureza sempre foi proporcionou condição de desenvolvimento ao homem, como alimentação e a continuidade de sua espécie. No entanto percebe-se certa inversão de valores atualmente. Na medida em que utilizamos de maneira excessiva os recursos naturais. Numa sociedade tecnologicamente desenvolvida, e altamente consumista levam a esgotamento da natureza e por consequência mais pobreza e conflitos por bens essenciais, como por exemplo: a água e alimentos (Lemos, et al., 2014).

A alimentação humana considerada, uma das necessidades básicas, enquanto condição para sua sobrevivência deve ser vista como algo mais que fornecedora de nutrientes, mas sim enquanto um valor que conforta (Sloan, 2005; Poulain, 2004).

Ao mesmo tempo a soberania alimentar valoriza preservação da cultura e aos hábitos alimentares de um país, por isso deve ser abordada de forma ética e comprometida, conforme Belik (2003).

Desta forma Westphal compreende que é preciso ter responsabilidade para com a vida dos seres humanos, principalmente num cenário de grandes avanços tecnológicos, mas que ao mesmo tempo ameaçam a própria espécie humana, como cita Westphal:

A responsabilidade para com o ser humano e a criação é fundamental para que se tomem decisões respeitosas diante dos avanços tecnológicos, para que estes não se transformem e ameaças à sobrevivência da humanidade. Na visão utilitarista, a ciência obedece à lógica da busca frenética por lucro. Muitas vezes, o objetivo da ciência é satisfazer as 
exigências do mercado. Não são o bem comum e o ser humano que estão na lista de suas prioridades, mas o lucro (Westphal, 2006, p.100).

Conceitos intrinsecamente ligados à preservação ambiental, a não utilização de agrotóxicos. Conforme afirma Ribeiro:

Quanto à oferta, a Segurança Alimentar pressupõe a garantia de que haja disponibilidade suficiente e sustentável de alimentos que respeitem a cultura alimentar, que sejam física e economicamente acessíveis à população e que propiciem opções saudáveis de alimentação. Isso requer, entre outros aspectos, o uso criterioso e sustentável dos recursos naturais da sociedade, o emprego de tecnologias seguras e eficientes e a execução de políticas governamentais que estimulem a produção e comercialização de alimentos saudáveis, não dispendiosos e compatíveis com a cultura alimentar local (Ribeiro et al., 2014, p. 45).

A falta de acesso a alimento se dá principalmente pela pobreza, a questão econômica ainda é fundamental para se explicar a insegurança alimentar. Nesta perspectiva se faz necessário um desenvolvimento sustentável, capaz de erradica-la, é crucial para melhorar o acesso aos alimentos. Outros eventos podem contribuir fatidicamente para tal feito como por exemplo: conflitos, terrorismo, corrupção e degradação do meio ambiente também contribuem significativamente para a insegurança alimentar. (FAO, 1996).

Evidentemente que o problema da fome vai muito além, ou seja, da fome e da desnutrição vão bem além da falta de alimento, a raiz deste problema está na falta de acesso ao alimento disponível, bem este essencial à sobrevivência e dignidade humana. Fundamentalmente, as raízes do problema da fome e desnutrição não residem na falta de alimento, mas na falta de acesso ao alimento disponível. Conforme afirma Callinicos: “A crise do sistema alimentar atual está enraizada na natureza das crises capitalistas, que para além de uma crise econômica, consiste em crises das relações sociais que fazem parte do processo cíclico do capitalismo" (Machado et al., 2016, p. 508).

Tendo em vista que a dimensão política do ato de alimentar-se, não ocorre isoladamente, mas nas relações sociais, perpassando o aspecto econômicos, dos processos produtivos, e como fim último seu acesso este bem essencial a sobrevivência humana, na busca por um bem-estar individual, associada à ideia de saúde, a partir da alimentação adequada, e analisada na perspectiva ética (Rosendo et al., 2019).

Assim numa relação considerada ética, não se pode agir com indiferença a fome alheia, nas palavras de Sen: “(...) necessidade de uma compreensão da justiça que seja baseada na realização está relacionada ao argumento de que a justiça não pode ser indiferente às vidas que as pessoas podem viver de fato" (Sen, 2011, p. 48). Desta forma se faz necessárias políticas públicas efetivas que venham a garantir bem como refletir sobre a proteção e respeito ao direito a alimentação, compreendido como direito humano fundamental, protegido pelo Estado.

\section{Conclusão}

A dignidade humana perpassa aquilo que é essencial ao ser humano, o ato de comer. O direito de alimentar-se acessando alimentos em quantidade e qualidade suficiente. Considera-se neste processo o direito de escolha ao alimento a partir da liberdade, da liberdade de escolha, tendo em vista o respeito aos indivíduos e às populações, respeitando sua cultura, suas tradições eticamente.

Apesar de este ser considerado um direito humano regido pela Constituição e defendido pelas organizações internacionais, nem sempre ele é respeitado. Comumente fatores de ordem econômica, ambientais, ou de ordem política impedem a fruição deste direito. Assim, nossa pesquisa evidencia que a dignidade humana só poderá ocorrer em sua plenitude quando a sociedade, bem como o Estado garantirem meios efetivos de forma coletiva a garantir a sustentabilidade ambiental do planeta, e ao mesmo tempo suprir as necessidades alimentares das populações, principalmente as mais vulneráveis. 
Research, Society and Development, v. 10, n. 10, e100101018677, 2021

(CC BY 4.0) | ISSN 2525-3409 | DOI: http://dx.doi.org/10.33448/rsd-v10i10.18677

\section{Referências}

Ahlert, A. (2007). Ética y Derechos Humanos: principios educacionales para una sociedad democrática. Polis [En línea], 16.

Almeida, L.M. M. C. (2007). Public policies and food security and family farming networks: contributions to the construction of effectiveness indicators.

Altieri, M. (2004). Agroecologia: a dinâmica produtiva da agricultura sustentável. (2. ed.). Editora da UFRGS.

Belik, W. (2003). Perspectivas para segurança alimentar e nutricional no Brasil. Saúde Soc. 2003; 12(1):12-20.

Brasil. (1988). Constituição da República Federativa do Brasil, Brasília.

Brasil. (2019). Lei no 13.844, de 18 de junho de 2019. Brasília, DF: Presidência da República, 2020a.

Brasil. (2019). Agroecológico. Em 7 anos, triplica o número de produtores orgânicos caastrados no Ministério da Agricultura.

Carneiro, F. F. \& Augusto, L. G. S. \& Rigotto, R. M. \& Friedrich, K. \& Búrgo, A.C. (2015). Dossiê ABRASO: um alerta sobre os impactos dos agrotóxicos na saúde. Vol. 1. São Paulo: Expressão Popular.

Cassal, V. B.; Azevedo, L. F. de; Ferreira, R. P.; Silva, D. G. \& Simão, R. S. (2014). Agrotóxicos: uma revisão de suas consequências para a saúde pública. http://dx.doi.org/10.5902/2236117012498 Revista do Centro do Ciências Naturais e Exatas - UFSM, Santa Maria Revista Eletrônica em Gestão, Educação e Tecnologia Ambiental - REGET e-ISSN 22361170 - V. 18 n. 1 Abr 2014, p.437-445

CEPAL (2020). Comissão Econômica para a América Latina e o Caribe. América Latina y el Caribe ante la pandemia del COVID-19: efectos económicos y sociales.

CONAB (2020). Companhia Nacional de Abastecimento. Safra 2019/2020. Brasília.

CONSEA (2017). Conselho Nacional de Segurança Alimentar e Nutricional. Segurança Alimentar e Nutricional e Soberania Alimentar.

Chomsky, N. (2017). Quem manda no mundo? Tradução de Renato Marques. Planeta, 400 p.

DIEESE (2020). Departamento Intersindical de Estatística e Estudos socioeconômicos. Pesquisa Nacional da Cesta Básica de Alimentos Tomada especial de preços de agosto de 2020 .

FAO (1996). Organização das Nações Unidas para Alimentação e Agricultura - Declaração de Roma sobre a segurança alimentar mundial e plano de ação da cimeira mundial da alimentação - Roma.

FAO (2017). Organização das Nações Unidas para a Alimentação e a Agricultura. América Latina E No Caribe. Panorama Da Segurança Alimentar E Nutricional: Sistemas alimentares sustentáveis para acabar com a fome e a e a má nutrição.

FAO (2017). Organization des Nations Unies puor I'alimentation et I' agriculture. L'état de la sécurité alimentaire et de la nutrition dans le monde.

FAO (2018). Organização das Nações Unidas para a Alimentação e a Agricultura. Panorama de la Seguridad Alimentaria y Nutricional: En América Latina Y El Caribe. Desigualdad Y Sistemas.

FAO (2020). Sistemas Alimentarios y COVID-19 en América Latina y el Caribe. $\mathrm{N}^{\circ}$ 3: riesgos que amenazan el comercio internacional. Garcia, M. (2004). Limites da ciência: dignidade da pessoa humana, ética da responsabilidade. São Paulo: Revista dos Tribunais.

Gil, A. C. (2010). Como elaborar projetos de pesquisa. (5. ed.). Atlas.

Hoffmann, R. (1994). A insegurança alimentar no Brasil. Revista Cadernos de Debate - UNICAMP, v. 2, p. 1-11.

IBGE (2020). Instituto Brasileiro de Geografia e Estatística. PNAD Contínua 2019: rendimento do $1 \%$ que ganha mais equivale a 33,7 vezes o da metade da população que ganha menos.

IBGE (2020). Instituto Brasileiro de Geografia e Estatística. Desemprego chega a 13,8\% no trimestre encerrado em julho, maior taxa desde 2012.

Kant, E. (2007). Fundamentação da metafísica dos costumes. Tradução: Paulo Quintela. Lisboa: Edições 70.

Lemos, P. F. I. (2014). Resíduos sólidos e responsabilidade civil pós-consumo. 3. ed. São Paulo: Revista dos Tribunais.

Machado, P. P \& Oliveira, N. R \& Mendes, Á. N. (2016). O indigesto sistema do alimento mercadoria. Saúde Soc. São Paulo, $25(2)$, p.505-515, 2016 505. DOI 10.1590/S0104-12902016151741

MAPA (2019). Ministério da Agricultura, Planejamento e Abastecimento. Alimentos orgânicos renderam R\$ 4 bilhões a produtores brasileiros em 2018.

Martinelli, S. S. \& Cavalli, S. B. (2019). Alimentação saudável e sustentável: uma revisão narrativa sobre desafios e perspectivas. Ciênc. Saúde Coletiva. 24(11). Rio de Janeiro.

MERCOSUL (2020). Mercado Comum do Sul. Comunicado conjunto de los presidentes de los Estados Partes del MERCOSUR y Estados Asociados.

MERCOSUL (2020). Mercado Comum do Sul. Comunicado conjunto de los Presidentes de los Estados Partes del MERCOSUR. 2020a.

Pansieri, F. (2016). Crítica de Amartya Sen à Concepção Rawlsiana de Justiça. Sequência (Florianópolis) [online]. 2016, n.74, pp.181-206. ISSN 21777055. https://doi.org/10.5007/2177-7055.2016v37n74p181. 
Research, Society and Development, v. 10, n. 10, e100101018677, 2021 (CC BY 4.0) | ISSN 2525-3409 | DOI: http://dx.doi.org/10.33448/rsd-v10i10.18677

Pereira, M. P. \& Oliveira, N. R. \& Mendes, A. N. (2016). O indigesto sistema do alimento mercadoria. Saúde soc. [online]. 2016, 25(2), 505-515. ISSN 19840470. http://dx.doi.org/10.1590/S0104-12902016151741.

Peres, F. M. (2003). Agrotóxicos, saúde e ambiente: uma introdução ao tema, pp. 21 - 41. In F Peres \& JC Moreira (orgs.). É veneno ou é remédio? Agrotóxicos, saúde e ambiente. Fiocruz, Rio de Janeiro.

Pessini, L. (2013). As origens da bioética: do credo bioético de Potter ao imperativo bioético de Fritz Jahr. Rev bioét (Impr.) $2013 ; 21$ (1): 9-19.

PLANSAN (2011). Plano Nacional de Segurança Alimentar e Nutricional 2012 -2015. Brasília.

PLANSAN (2017). Plano Nacional de Segurança Alimentar e Nutricional: PLANSAN 2016 - 2019. Brasília.

PLANSAN (2018). II Plano Nacional de Segurança Alimentar e Nutricional: PLANSAN 2016 - 2019. Revisado, Brasília.

Poulain, J. P. (2004). Sociologias da alimentação: os comedores e o espaço social alimentar. Florianópolis: UFSC.

Rosendo, D. \& Kuhnen, T. A. (2019). Direito à Alimentação: direito, consumo, política e ética no Brasil. Novos Estudos Jurídicos. UNIVALI. Doi: 10.14210/nej.v24n2.p562-588

Ribeiro, C. S. G \& Pilla, M. C. B. A. (2014). Segurança alimentar e nutricional: interfaces e diminuição de desigualdades sociais. Demetra: alimentação, nutrição \& saúde. Demetra; 2014; 9(1); 41-52DOI: 10.12957/demetra.2014.664

Sá, M. A. \& Gonçalves, E. B. \& Souza, V. A. B. \& Lapolli, É. M. (2014). Produtores orgânicos e a sustentabilidade. Revista Brasileira de Agroecologia Rev. Bras. de Agroecologia. 9(2): 84-97 (2014) ISSN: 1980-9735

Sarlet, I. W. (2007). Dignidade da pessoa humana e direitos fundamentais na Constituição de 1988. Livraria do Advogado.

Sen, A. (2011). A Ideia de Justiça. São Paulo: Companhia das Letras.

Sloan, D. (2005). Gastronomia, restaurantes e comportamento do consumidor. Barueri: Manole.

Silvério, F. O. ; Silva, J. G. S.; Aguiar, M. C. S.; Cacique, A. P. \& Pinho, G. P. (2012) Análise de agrotóxicos em água usando extração líquido-líquido com partição em baixa temperatura por cromatografia líquida de alta eficiência. Química Nova, 35(10), 2052-2056.

Soares, C. S.; Roesler, R. v. B. \& Signor, A. (2020). Políticas Públicas: juventude brasileira e o direito a sustentabilidade Ambiental. Environmental Scientiae, 2(2), 25-38, 2020. DOI: http://doi.org/10.6008/CBPC2674-6492.2020.002.0003

SOFI (2020). Relatório State of Food Security and Nutrition in the World 2020.

Stopelli, I. M. S. \& Magalhães, C. P. (2005). Saúde e segurança alimentar: a questão dos agrotóxicos. Ciência e Saúde Coletiva, 10(sup): 91-100.

Westphal, E. R. (2006). Bioética. São Leopoldo. Sinodal. 